of insecticides under various climatic conditions, are also given in the report. In addition to the description of test procedures, the annexes contain sampling instructions, and an account of a provisional method for testing aerosols which has been successfully employed in the United States of America. For those-whether manufacturers or buyers-who are obliged to keep abreast of the latest developments in this field, this report is a valuable source of information.

\section{Register of Specialist Indexers}

To assist authors and publishers in achieving a high standard of indexing in their published works, Aslib (formerly the Association of Special Libraries and Information Bureaux) is establishing a register of specialist indexers. The register will consist of persons who are available for part-time indexing only; a staff employment register is already maintained for indexers and other library staff seeking full-time employment of either a temporary or permanent nature. Indexers will be enrolled in two categories: those who can produce evidence of indexing ability, and those who appear to possess the necessary qualifications but who have no published indexes to their credit. In both cases, evidence of special knowledge of one or more subjects will be required, so as to ensure competence in handling technical and other specialized material. All indexing work negotiated through the Aslib register will be subject to scrutiny and report as a means of ensuring that the register becomes and remains a recognized source of reliable subject indexers. Inquiries should be addressed to the Director, Aslib, 4 Palace Gate, London, W.8. Under the terms of the register, which is licensed annually by the London County Council, no charge will be made to employers but a small enrolment fee and commission will be charged to those indexers who are accepted for enrolment, unless they are personal members of Aslib, when no charge will be made.

\section{High-Altitude Research Laboratory in Alaska}

A pERMANENT high-altit ude observatory for research in cosmic radiation, high-altitude biology, and meteorology is in the course of being established on the summit of Mt. Wrangell (14,006 ft.), a dormant volcano in Alaska, by an expedition led by Dr. Serge A. Korff, professor of physics in New York University, and Dr. Terris Moore, president of the University of Alaska (see Nature, June 27, p. 1140). It has now been announced that a party of five has climbed the mountain on foot, arriving at the summit on July 1 . It included Arthur Beiser and Hugo Neuburg, graduate students of New York University ; Charles Wilson, of the University of Alaska; Philip Bettler, of the Geophysical Institute ; and Robert Goodwin, of Anchorage. They were the second group ever to reach the summit, the first successful ascent having been made in 1908. Two Jamesway huts and related supplies and equipment have been dropped to the party by a private plane piloted by Dr. Moore. One of the luts is used as living quarters by the research workers; the other is a laboratory housing scientific supplies and equipment.

Solar Variation and Precipitation at Peoria, Illinois

A PAPER entitled "Solar Variation and Precipitation at Peoria, Illinois" has been published by Dr. C. G. Abbot (Smithson. Misc. Coll., 117, No. 16 ; Sept. 3, 1952), in which he returns to the subject of twenty- three periodic changes in the intensity of the solar radiation, a problem to which attention has already been directed (Smithson. Mise. Coll., 117, No. 10; 1952). Dr. Abbot has been engaged for more than three years in investigations of precipitation records between 1856 and 1939, and in the present paper shows that periodicities of the same length as nineteen of those discovered in solar variation are accompanied by changes of 5-20 per cent amplitude in the precipitation at Peoria. Four graphs show how these periodic variations of precipitation occur in nearly equal amplitudes and with moderate differences of phase in twelve separate independent intervals, each several years long. Using these results as a basis, predictions of the precipitation for Peoria during 1940-50 are made and the results are very satisfactory. The actual precipitation ranges from 50 to 150 per cent of normal, and prediction matches the event for eight out of eleven years to within an average deviation of $14 \cdot 7$ per cent. Large fluctuations in precipitation during the other three years were matched by similar large fluctuations in the curve of prediction, but with phase differences varying from three to six months. It is admitted that it is difficult to understand how solar changes generally less than 0.2 per cent can produce variations in precipitation of 5-20 per cent; but, in spite of this, these periodic changes of precipitation have been synthesized to forecast seasons. One of the graphs in the paper shows the predioted precipitation at Peoria during 1940-50, and for the first three years there is fajr agreement between prediction and event; but after 1942 there was change of phase, though not of form, and changes of phase mar long-range predictions. Dr. Abbot adds at the end of the paper that, unless the phase-changes can be anticipated, the method of prediction fails to come up fully to expectation.

\section{Library of the University of Leeds : Annual Report}

THE annual report of the librarian of the University of Leeds for the session 1951-52 (pp. 16; 1952) records holdings on June 30,1952 , of 351,847 books and 155,278 pamphlets; accessions during the year numbered 14,130 and 3,564, respectively, and, compared with the first year of the quinquennium just ended (1947-48), the total stock increased by 20 per cent and annual accessions by 28 per cent, due partly to increased book funds, especially in the form of non-recurrent grants from the University Grants Committee and from the Council. The rate of additions to the catalogue increased by 144 per cent, and the growth of the main author catalogue presents a serious problem of accommodation. Binding increased in bulk by 62 per cent and is now limited chiefly by finance. The annual number of loans increased by 56 per cent, and inter-library loans were developed as a matter of policy ; the Library borrows extensively from other libraries in the region and throughout Britain and abroad, and lends extensively in return, especially to other universities and to public libraries in the Yorkshire Regional Library System. Hopes that during the new quinquennium a systematic effort could be made to fill some of the more serious gaps in the collections are unlikely to be realized, and it is probable that a main concern will be to avoid an undue decrease in the intake of current publications in view of the constantly rising cost of books. The successful display of French scientifie publications was followed in January 1952 by an equally successful exhibition of Dutch learned publications. 